\title{
The Efficacy of Saffron in the Treatment of Mild to Moderate Depression: A Meta-analysis
}

Authors

Barbara Tóth $^{1,2}$, Péter Hegyi ${ }^{3}$, Tamás Lantos ${ }^{4}$, Zsolt Szakács ${ }^{3}$, Beáta Kerémi ${ }^{5}$, Gábor Varga ${ }^{5}$, Judit Tenk ${ }^{3}$, Erika Pétervári ${ }^{3}$, Márta Balaskó ${ }^{3}$, Zoltán Rumbus ${ }^{3}$, Zoltán Rakonczay ${ }^{6}$, Emese Réka Bálint ${ }^{6}$, Tivadar Kiss ${ }^{1,2}$, Dezső Csupor $^{1,2}$

Affiliations

1 Department of Pharmacognosy, Faculty of Pharmacy, University of Szeged, Szeged, Hungary

2 Interdisciplinary Centre of Natural Products, University of Szeged, Szeged, Hungary

3 Institute for Translational Medicine, Medical School, University of Pécs, Pécs, Hungary

4 Department of Medical Physics and Informatics, Faculty of Medicine, University of Szeged, Szeged, Hungary

5 Department of Oral Biology, Faculty of Dentistry, Semmelweis University, Budapest, Hungary

6 Department of Pathophysiology, University of Szeged, Szeged, Hungary

Key words

saffron, Crocus sativus, Iridaceae, depression, meta-analysis

received May 18, 2018

revised July 2, 2018

accepted July 13, 2018

Bibliography

DOI https://doi.org/10.1055/a-0660-9565

Published online July 23, 2018 | Planta Med 2019; 85: 24-31

(c) Georg Thieme Verlag KG Stuttgart · New York ।

ISSN 0032-0943

Correspondence

Dr. Dezső Csupor

Department of Pharmacognosy, Faculty of Pharmacy,

University of Szeged

Eotvos u. 6., 6720 Szeged, Hungary

Phone: + 36625455 59, Fax: + 3662545704

csupor.dezso@pharmacognosy.hu

$\Theta$

Supporting information available online at

http://www.thieme-connect.de/products
ABSTRACT

Herbal products, especially Hypericum perforatum extracts, have been widely used as first-line treatments for mild to moderate depression. Recently, several randomized, controlled clinical trials have been conducted to evaluate the efficacy of another plant, saffron (Crocus sativus), in mild to moderate depression. We have carried out a literature review of currently available published randomized, controlled clinical trials to give an up-to-date evaluation of the efficacy of saffron in mild to moderate depression, compared to placebo or routinely used antidepressants. The meta-analysis is reported according to the preferred reporting items for systematic reviews and meta-analyses (PRISMA) guidelines using the PICO (patients, intervention, comparison, outcome) format and was conducted using the statistical programs Comprehensive Meta-analysis and RevMan. PubMed, Embase, the Cochrane Central Register of Controlled Trials, and Web of Science databases were searched for relevant studies. Only placebo or active controlled, randomized clinical studies involving patients suffering from mild to moderate depression and using pharmacological doses of saffron per os were included. Hedges' $g$ was used to calculate effect sizes. Risk of bias was assessed using the Cochrane Collaboration tool, and heterogeneity was tested by both performing the Cochran's $Q$ test and calculating Higgins' $P$ indicator. Eleven randomized trials were included in the qualitative analysis, and nine were pooled for statistical analysis. According to the present meta-analysis, saffron has a significant effect on the severity of depression. Available data from randomized, controlled clinical trials support that saffron is significantly more effective than placebo ( $g=0.891 ; 95 \% \mathrm{Cl}: 0.369-1.412, \mathrm{p}=0.001)$, and non-inferior to tested antidepressant drugs $(\mathrm{g}=-0.246$; $95 \% \mathrm{Cl}$ : $-0.495-$ 0.004, $\mathrm{p}=0.053$ ).

\section{Introduction}

According to the World Health Organization, depression affects 300 million people worldwide [1], and is a leading cause of disability. For the treatment of mild or moderate depression in adults, several types of antidepressants are available, including TCAs,
MAOIs, SSRIs, SNRIs, NDRIs, and SARIs [2,3]. However, initial antidepressant therapy may not provide adequate relief for the patient, either because of the medicine's adverse reactions or because of the lack of immediate efficacy. Therefore, novel agents with a more favorable safety profile and efficacy are needed. Herbs may provide an alternative to synthetic antidepressants 


\begin{tabular}{|c|c|}
\hline \multicolumn{2}{|c|}{ ABBREVIATIONS } \\
\hline BDI & Beck Depression Inventory \\
\hline DSM & Diagnostic and Statistical Manual of Mental \\
\hline & Disorders \\
\hline HAM-D & Hamilton Depression Rating Scale \\
\hline MAOIs & monoamine oxidase inhibitors \\
\hline NDRIs & norepinephrine and dopamine reuptake inhibitors \\
\hline PRISMA & $\begin{array}{l}\text { Preferred Reporting Items for Systematic Reviews } \\
\text { and Meta-Analyses }\end{array}$ \\
\hline $\mathrm{RCT}$ & randomized controlled trial \\
\hline SARIs & serotonin antagonist and reuptake inhibitor \\
\hline SNRIs & serotonin and norepinephrine reuptake inhibitors \\
\hline SSRI & selective serotonin reuptake inhibitor \\
\hline TCAs & tricyclic antidepressants \\
\hline
\end{tabular}

with a better balance of benefits and potential harms [4], as has been confirmed for Hypericum perforatum, which is the active component of several marketed medicines.

Crocus sativus L. (saffron), belonging to the Iridaceae family, is one of the most expensive spices in the world, and it has been used as a medicinal plant in traditional Arabic and Islamic medicine for hundreds of years [5]. Its major bioactive secondary metabolites, possessing a significant antioxidant activity, include crocin, picrocrocin, safranal, and crocetin [6]. Several preclinical studies have confirmed the antidepressant effects of crocin and crocetin [7]. Recently, the antidepressant activity of some antioxidants has also been evaluated, and $\mathrm{N}$-acetylcysteine as well as curcumin are reported to have the potential to ameliorate depressive symptoms $[8,9]$. Meta-analyses support that serum total antioxidant capacity and antioxidant levels might be lower, while serum free radical and oxidative damage product levels might be higher in depressed patients than in healthy controls $[10,11]$. Thus, herbs with a significant antioxidant content, such as saffron, may have a promising antidepressant activity, and, therefore, they are worth being studied. However, so far, little is known about the mechanism of action of saffron in depression.

Although several RCTs have been conducted to evaluate the effectiveness of saffron in mild to moderate depression, the robustness of findings from individual studies have not been reassessed statistically in a meta-analysis. Therefore, the aim of the present literature review and meta-analysis was to synthesize currently available published evidence and evaluate the antidepressant efficacy of saffron, and to assess the safety profile of the plant based on the included trials. In order to complete this task, the following PICO (patients, intervention, comparison, outcome) format was applied: $\mathrm{P}=$ patients with mild to moderate depression, $\mathrm{I}$ = pharmacological doses of saffron given per os, $\mathrm{C}$ = placebo or routinely used antidepressant, and $\mathrm{O}=$ changes in the severity of the depression.

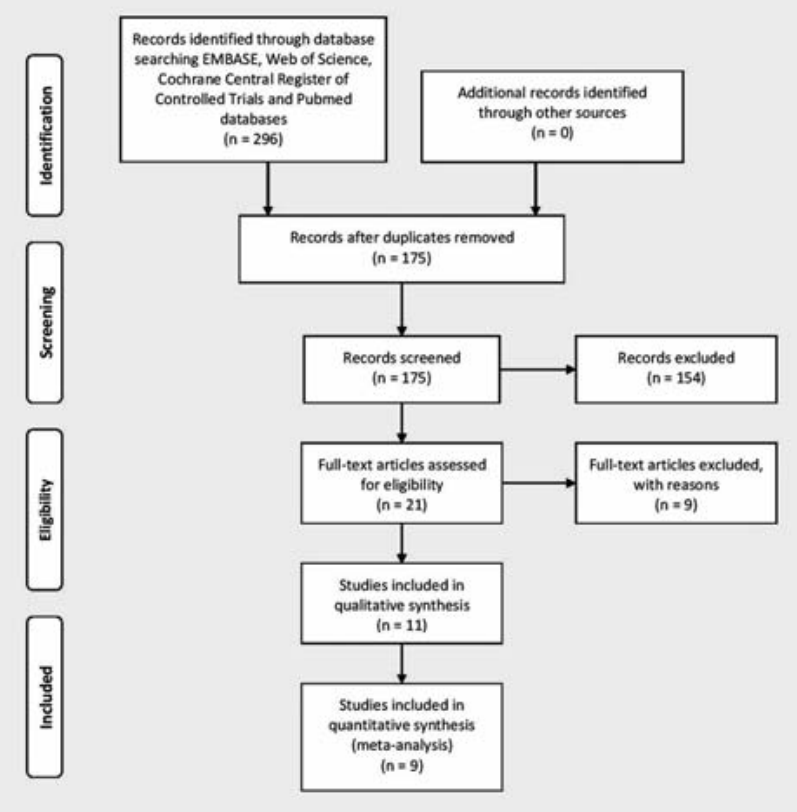

- Fig. 1 PRISMA 2009 flow diagram for identification of relevant studies.

\section{Results}

Literature searches were performed in Embase, PubMed, Cochrane Central Register of Controlled Trials, and Web of Science databases using the search terms saffron and depression. After removing duplicates, the search yielded a total of 175 potentially relevant reports. Eligible RCTs were selected according to the flow chart presented in $>$ Fig. 1.

After screening titles and abstracts (Table 1S, Supporting Information), 21 publications were retrieved for full-text screening, of which 9 RCTs were also excluded: in 2 studies, the effects of saffron products were analyzed without a comparator $[12,13]$, and in 4 RCTs, saffron was combined with nutraceuticals $[14,15]$ or fluoxetine $[16,17]$. In two studies, the effects of purified crocin was evaluated $[18,19]$, and the aim of our meta-analysis was to focus on the efficacy of $C$. sativus rather than on its purified compounds. In one study [20], the patients involved were not suffering from mild to moderate depression, therefore, this study did not comply with our PICO. After reviewing the articles, it became clear that one trial, including three treatment arms, was published in two different papers $[21,22]$. Consequently, we considered these two papers as one RCT. Therefore, a total of 11 placebocontrolled, randomized trials with 531 patients were included in the qualitative analysis [21-32].

Altogether, ten articles reporting on nine trials were included in our final quantitative analysis [21-27,29-31]. Akhondzadeh et al. [32] provided the baseline HAM-D scores numerically, but the outcomes were shown only graphically in a figure, therefore, we could not include the results of this trial in the quantitative analysis. However, the authors claim that saffron $(30 \mathrm{mg} /$ day) and imipramine ( $100 \mathrm{mg} /$ day) treatment for 6 weeks resulted in signif- 
icant ( $p<0.0001)$ improvement of HAM-D scores in mild to moderate depression. Another publication was also ineligible for further quantitative analysis, because of only the change in BDI-IA scores, and neither the baseline values nor the outcome were published [28]. In this trial, saffron had a significant effect on BDI scores compared to placebo after 12 weeks of administration.

Overall, the methodological quality of the trials included in our final quantitative analysis was reckoned to be acceptable, mostly with a low or unclear risk of bias. Most of the studies showed a low risk of randomization bias. The study published in two different papers [21,22] included a contradictory description of randomization, so these two papers were judged to have a high risk of randomization bias. Tabeshpour et al. [25] failed to describe the methods used for random sequence generation, allocation and blinding; therefore, this study was reckoned to have an unclear risk of selection, performance, and detection bias. In three studies, patients were assessed several times during the study, but only the results of the last assessment were presented numerically in the publications $[21,22,30,31]$. Therefore, attrition bias and reporting bias for these studies remained unclear. In three papers $[21,22,31]$ that report on two studies, it was not mentioned whether the intervention and the comparator were identical in size, shape, color, and odor. In one study [30], the person who accomplished the randomization performed the allocation too, and therefore allocation bias of this RCT was unclear. Studies with an unclear risk of other bias did not report on the exact baseline scores regarding the severity of depression [21, 22, 25, 29, 31].

All the included clinical trials were conducted in Iran, where saffron is easily accessible [33], from 2004 until 2018. D Table 1 summarizes the key characteristics of each study. Compared to a previous meta-analysis last published on this topic [34], seven subsequent RCTs were included in our meta-analysis. Sample size of RCTs assessed ranged from 30 to 64 patients, and the effects of saffron were investigated in adults with different comorbidities or associated conditions ( $\vee$ Table $\mathbf{1}$ ).

Only studies assessing well-characterized saffron products and using pharmacological doses of saffron were included in our meta-analysis. In four studies, a commercially available product, SaffroMood, was used [23, 26, 27, 29]. Each SaffroMood capsule contained $15 \mathrm{mg} 80 \%$ ethanolic dry extract of the stigma of $C$. sativus, and it was standardized to crocin (1.65-1.75 mg/capsule). Abedimanesh et al. [24] used the aqueous extract of saffron stigma, and in two RCTs, an $80 \%$ ethanol extract of saffron stigma was encapsulated [21, 22, 32]. In the RCT reported by Noorbala et al. [22] and Akhondzadeh et al. [21], each capsule contained a saffron extract with $0.30-0.35 \mathrm{mg}$ safranal content. In two trials, dried saffron stigma was used $[25,28]$. Each tablet administered in the study by Tabeshpour et al. [25] contained $5 \pm 0.25 \mathrm{mg}$ of crocin. In two trials, the efficacy of the petal extract of $C$. sativus was determined [30,31].

The majority of the studies lasted 6 weeks, while 2 studies examined the effects of saffron after 8 weeks of administration [24, $25,30]$, and one study was 12 weeks long [28] ( $>$ Table 2 ).

The efficacy of saffron versus the comparator (placebo or the antidepressant drug) was assessed based on the changes in the severity of depression. Extracted outcomes regarding changes in depression severity are listed in $\mathbf{r}$ Table $\mathbf{2}$. In the included RCTs, the severity of depression was characterized in two different ways. In eight studies [21-22,23,26,27,29-30,31,32], the HAM-D was used [35]. In one RCT [28], the revised BDI-IA [36] was applied, and in two studies [24,25] the BDI-second edition [37] was used. The original BDI includes 21 items concerning different symptom domains, with four possible answers describing the symptoms. It was revised to BDI-IA, and then to BDI-second edition (BDI-II) after the DSM-IV was published. Four new items were added to $\mathrm{BDI}-\mathrm{IA}$ to make the $\mathrm{BDI}-\mathrm{II}$ more reflective of the DSM-IV criteria of major depressive disorders, and some BDI-IA items were eliminated because they were considered to be less indicative of the overall severity of depression.

RCT results on the antidepressant efficacy of saffron versus placebo were examined combined, regardless of the scale (HAM-D or BDI) used for assessing the therapeutic effect. Thus, the results of five trials were analyzed combined: three trials reported the changes in HAM-D scores [21, 23, 31], and two used BDI-II $[24,25]$. Results of this combined analysis support that saffron significantly reduces the severity of mild to moderate depression compared to placebo, as demonstrated by the random effect model $\left(Q=14.490, \mathrm{df}=4, \mathrm{p}=0.006, P^{2}=72.4 \%\right): \mathrm{g}=0.891$; lower limit of $95 \% \mathrm{Cl}[\mathrm{LL}]: 0.369$, upper limit of $95 \% \mathrm{Cl}$ [UL]: 1.412 , $\mathrm{p}=0.001$ ( $\triangleright$ Fig. 2 ).

RCT results on the antidepressant efficacy of saffron versus any accepted antidepressant drug treatments were also examined combined. In four trials, the SSRI fluoxetine [22, 27, 29,30] and, in one trial, the SSRI citalopram [26] served as a comparator. Antidepressants generally seem to be more effective than saffron, but the result of our meta-analysis failed to show a significant difference between saffron and SSRIs. In this case, a fixed effect model was applied $(Q=1.149, \mathrm{df}=4, \mathrm{p}=0.886, R=0 \%): \mathrm{g}=-0.246$; lower limit of $95 \% \mathrm{Cl}$ [LL]: -0.495 , upper limit of $95 \% \mathrm{Cl}$ [UL]: $0.004, p=0.053$ ( $>$ Fig. 3).

The findings of the present meta-analysis also support the relative safety of $C$. sativus. In an included trial, none of the patients reported any adverse reactions after treatment with a saffron preparation [31]. Abedimanesh et al. [24] did not report adverse reactions as an outcome. In all other included trials, patients experienced various adverse reactions, such as drowsiness, sedation, anxiety, headache, sweating, nausea, changes in appetite, constipation, dry mouth, palpitation, and tremor. After collecting data on all reported adverse reactions, the results were analyzed by Fisher's exact test (two-sided). The incidence of the reported adverse reactions was not significantly different from that associated with placebo (Table 2S, Supporting Information). Patients who received the TCA imipramine experienced sedation $(p=0.017)$ and dry mouth $(p=0.035)$ significantly more often than patients in the saffron group [32]. Otherwise, the incidence of adverse reactions was not significantly different between the treatment arms in any of the included studies. After combining all available safety data, we concluded that tremors occurred significantly more often $(p=0.047)$ in the SSRI group than in the saffron group (Table 3S, Supporting Information) [22, 30]. 
- Table 1 Characteristics of the studies included (all placebo-controlled, randomized trials) in the final qualitative analysis.

\begin{tabular}{|c|c|c|c|c|c|c|c|}
\hline $\begin{array}{l}\text { First author } \\
\text { (year) }\end{array}$ & Country & $\begin{array}{l}\text { Patient } \\
\text { characteristics }\end{array}$ & $\begin{array}{l}\text { Characteristics of the } \\
\text { applied saffron product/ } \\
\text { dosage form }\end{array}$ & Groups & $\begin{array}{l}\text { Baseline } \\
\text { score } \\
\text { type }\end{array}$ & $\begin{array}{l}\text { Baseline score } \\
\text { (mean } \pm \text { SEM) }\end{array}$ & $\begin{array}{l}\text { Severity of } \\
\text { depression }\end{array}$ \\
\hline \multirow{2}{*}{$\begin{array}{l}\text { Kashani } \\
\text { (2018) [23] }\end{array}$} & \multirow[t]{2}{*}{ Iran } & \multirow{2}{*}{$\begin{array}{l}\text { Post-menopausal } \\
\text { women with clinical } \\
\text { diagnosis of hot flashes }\end{array}$} & \multirow{2}{*}{$\begin{array}{l}15 \text { mg saffron extract/ } \\
\text { capsule (SaffroMood, } \\
\text { Green Plant Life/IMPIRAN) }\end{array}$} & saffron & \multirow[t]{2}{*}{ HAM-D } & $15.29 \pm 1.14$ & \multirow[t]{2}{*}{ mild } \\
\hline & & & & placebo & & $15.96 \pm 0.81$ & \\
\hline \multirow{2}{*}{$\begin{array}{l}\text { Abedimanesh } \\
\text { (2017) [24] }\end{array}$} & \multirow[t]{2}{*}{ Iran } & \multirow{2}{*}{$\begin{array}{l}\text { Patients with coronary } \\
\text { artery disease }\end{array}$} & \multirow{2}{*}{$\begin{array}{l}30 \mathrm{mg} \text { aqueous saffron } \\
\text { extract/capsule }\end{array}$} & saffron & \multirow[t]{2}{*}{ BDI-II } & $26.10 \pm 2.68$ & \multirow[t]{2}{*}{ moderate } \\
\hline & & & & placebo & & $27.42 \pm 2.16$ & \\
\hline \multirow{2}{*}{$\begin{array}{l}\text { Tabeshpour } \\
(2017)[25]\end{array}$} & \multirow[t]{2}{*}{ Iran } & \multirow[t]{2}{*}{ Breastfeeding mothers } & \multirow[t]{2}{*}{$15 \mathrm{mg}$ saffron/tablet } & saffron & \multirow[t]{2}{*}{ BDI-II } & $20 \pm 5.7$ & \multirow{2}{*}{$\begin{array}{l}\text { mild/ } \\
\text { moderate }\end{array}$} \\
\hline & & & & placebo & & $19.7 \pm 5.3$ & \\
\hline \multirow{2}{*}{$\begin{array}{l}\text { Kashani } \\
\text { (2017) [27] }\end{array}$} & \multirow[t]{2}{*}{ Iran } & \multirow{2}{*}{$\begin{array}{l}\text { Patients with post- } \\
\text { partum depression }\end{array}$} & \multirow{2}{*}{$\begin{array}{l}15 \text { mg saffron extract/ } \\
\text { capsule (SaffroMood, } \\
\text { Green Plant Life/IMPIRAN) }\end{array}$} & saffron & \multirow[t]{2}{*}{ HAM-D } & $16.53 \pm 0.26$ & \multirow{2}{*}{$\begin{array}{l}\text { mild/ } \\
\text { moderate }\end{array}$} \\
\hline & & & & fluoxetine & & $16.65 \pm 0.20$ & \\
\hline \multirow{2}{*}{$\begin{array}{l}\text { Ghajar (2017) } \\
\text { [26] }\end{array}$} & \multirow[t]{2}{*}{ Iran } & \multirow{2}{*}{$\begin{array}{l}\text { Patients suffering from } \\
\text { major depressive } \\
\text { disorder accompanied } \\
\text { by anxious distress }\end{array}$} & \multirow{2}{*}{$\begin{array}{l}15 \text { mg saffron extract/ } \\
\text { capsule (SaffroMood, } \\
\text { Green Plant Life/IMPIRAN) }\end{array}$} & saffron & \multirow[t]{2}{*}{ HAM-D } & $17.20 \pm 0.26$ & \multirow[t]{2}{*}{ moderate } \\
\hline & & & & citalopram & & $17.50 \pm 0.12$ & \\
\hline \multirow{2}{*}{$\begin{array}{l}\text { Mazidi (2016) } \\
{[28]}\end{array}$} & \multirow[t]{2}{*}{ Iran } & \multirow{2}{*}{$\begin{array}{l}\text { Patients with mild to } \\
\text { moderate depression }\end{array}$} & 50 mg dried stigma/cap- & saffron & BDI-IA & $10-30$ & mild/ \\
\hline & & & sule (Novin Saffron Co.) & placebo & & $10-30$ & moderate \\
\hline Shahmansouri & Iran & Patients who under- & 15 mg saffron extract/ & saffron & HAM-D & $17.00 \pm 0.40$ & mild/ \\
\hline (2014) [29] & & $\begin{array}{l}\text { went percutaneous } \\
\text { coronary intervention }\end{array}$ & $\begin{array}{l}\text { capsule (SaffroMood, } \\
\text { Green Plant Life/IMPIRAN) }\end{array}$ & fluoxetine & & $16.80 \pm 0.40$ & moderate \\
\hline Basti (2007) & Iran & Depressed outpatients & 15 mg ethanolic ( $80 \%$ & saffron & HAM-D & $\geq 21$ and $\leq 23$ & moderate \\
\hline & & & $\begin{array}{l}\text { ethanol) extract of the } \\
\text { petal/capsule }\end{array}$ & fluoxetine & & & \\
\hline Moshiri (2006) & Iran & Adult outpatients & $15 \mathrm{mg}$ ethanolic ( $80 \%$ & saffron & HAM-D & $\geq 21$ and $\leq 23$ & moderate \\
\hline & & & $\begin{array}{l}\text { ethanol) extract of the } \\
\text { petal/capsule }\end{array}$ & placebo & & & \\
\hline Noorbala & Iran & Adult outpatients & 15 mg etanolic ( $80 \%$ etha- & saffron & HAM-D & $\geq 22$ and $\leq 24$ & moderate \\
\hline (2005) [22] & & & $\begin{array}{l}\text { nol) saffron extract/cap- } \\
\text { sule (Novin Saffron Co.) }\end{array}$ & fluoxetine & & & \\
\hline Akhondzadeh & Iran & Adult outpatients & 15 mg etanolic ( $80 \%$ etha- & saffron & HAM-D & $\geq 22$ and $\leq 24$ & moderate \\
\hline (2005) [21] & & & $\begin{array}{l}\text { nol) saffron extract/cap- } \\
\text { sule (Novin Saffron Co.) }\end{array}$ & placebo & & & \\
\hline Akhondzadeh & Iran & Adult outpatients & 15 mg etanolic ( $80 \%$ etha- & saffron & HAM-D & $19.20 \pm 0.11$ & moderate \\
\hline (2004) [32] & & & $\begin{array}{l}\text { nol) saffron extract/cap- } \\
\text { sule (Novin Saffron Co.) }\end{array}$ & imipramine & & $19.00 \pm 0.11$ & \\
\hline
\end{tabular}

\section{Discussion}

The present meta-analysis was designed to synthesize currently available evidence on the usage of saffron in the treatment of mild to moderate depression. A comprehensive literature search yielded seven recently published trials besides those included in a previous and last published meta-analysis on this topic [34].

Based on our most up-to-date meta-analysis, saffron (C. sativus) is statistically significantly superior to placebo in the treatment of mild to moderate depression, and non-inferior to SSRI antidepressants (fluoxetine, citalopram). Limitations of our literature review and meta-analysis are largely related to the primary studies. All the included trials were performed in Iran. In several trials, patients with various comorbidities (e.g., coronary artery disease) were included, yielding an inhomogeneous patient population for the meta-analysis, and it is reasonable to assume that this factor may have influenced the primary results regarding treatment efficacy. The authors of several papers are overlapping, suggesting that their preconceptions about the efficacy of saffron may have caused bias in the RCTs as well. The number of trials reporting the same outcomes was too low to properly assess publication bias by funnel plots or by performing Egger's test. Nevertheless, 11 RCTs, including a total of more than 500 patients (256 of whom received saffron), demonstrated both the superiority of saffron versus placebo, and non-superiority compared to SSRIs (fluoxetine, citalopram).

Saffron is considered to be safe even in amounts much higher than the typical use, up to daily doses of $1.5 \mathrm{~g}$ [38]. One study concluded that higher doses of saffron (200-400 mg daily) may cause alterations of some hematological and biochemical parameters, but these changes are within the normal limits [39]. Despite its relative safety, saffron may cause allergic reactions. According 
- Table 2 Published outcomes of the included clinical trials.

\begin{tabular}{|c|c|c|c|c|c|c|c|c|}
\hline $\begin{array}{l}\text { First author } \\
\text { (year) }\end{array}$ & Group & $\begin{array}{l}\text { Daily } \\
\text { dose }\end{array}$ & $\begin{array}{l}\text { Sample } \\
\text { size }\end{array}$ & $\begin{array}{l}\text { Treatment } \\
\text { duration } \\
\text { (weeks) }\end{array}$ & $\begin{array}{l}\text { Reduction of } \\
\text { HAM-D score } \\
\text { from baseline } \\
\text { to study end } \\
\text { (mean } \pm \text { SEM) }\end{array}$ & $\begin{array}{l}\text { BDI-II score, } \\
\text { baseline } \\
\text { (mean } \pm \text { SEM) }\end{array}$ & $\begin{array}{l}\text { BDI-II score } \\
\text { after } 8 \text { weeks } \\
\text { (mean } \pm \text { SEM) }\end{array}$ & $\begin{array}{l}\text { Reduction of } \\
\text { BDI-IA score } \\
\text { from baseline } \\
\text { to study end } \\
\text { (mean } \pm \text { SEM) }\end{array}$ \\
\hline \multirow{2}{*}{$\begin{array}{l}\text { Kashani } \\
\text { (2018) [23] }\end{array}$} & saffron & $30 \mathrm{mg}$ & 28 & 6 & $7.10 \pm 0.83$ & - & - & - \\
\hline & placebo & - & 28 & 6 & $4.39 \pm 0.83$ & - & - & - \\
\hline \multirow{2}{*}{$\begin{array}{l}\text { Abedimanesh } \\
\text { (2017) [24] }\end{array}$} & saffron & $30 \mathrm{mg}$ & 20 & 8 & - & $26.10 \pm 2.68$ & $21.05 \pm 2.68$ & - \\
\hline & placebo & - & 19 & 8 & - & $27.42 \pm 2.16$ & $27.47 \pm 2.16$ & - \\
\hline \multirow{2}{*}{$\begin{array}{l}\text { Tabeshpour } \\
\text { (2017) [25] }\end{array}$} & saffron & $30 \mathrm{mg}$ & 30 & 8 & - & $20 \pm 5.7$ & $8.4 \pm 3.7$ & - \\
\hline & placebo & - & 30 & 8 & - & $19.7 \pm 5.3$ & $15.3 \pm 5.4$ & - \\
\hline \multirow{2}{*}{$\begin{array}{l}\text { Kashani } \\
\text { (2017) [27] }\end{array}$} & saffron & $30 \mathrm{mg}$ & 32 & 6 & $7.50 \pm 0.35$ & - & - & - \\
\hline & fluoxetine & $40 \mathrm{mg}$ & 32 & 6 & $7.71 \pm 0.30$ & - & - & - \\
\hline \multirow{2}{*}{$\begin{array}{l}\text { Ghajar (2017) } \\
\text { [26] }\end{array}$} & saffron & $30 \mathrm{mg}$ & 30 & 6 & $10.13 \pm 1.09$ & - & - & - \\
\hline & citalopram & $40 \mathrm{mg}$ & 30 & 6 & $11.27 \pm 0.67$ & - & - & - \\
\hline \multirow{2}{*}{$\begin{array}{l}\text { Mazidi (2016) } \\
{[28]}\end{array}$} & saffron & $100 \mathrm{mg}$ & 24 & 12 & - & - & - & $6.69 \pm 2.73$ \\
\hline & placebo & - & 30 & 12 & - & - & - & $4.35 \pm 4.60$ \\
\hline \multirow{2}{*}{$\begin{array}{l}\text { Shahman- } \\
\text { souri (2014) } \\
{[29]}\end{array}$} & saffron & $30 \mathrm{mg}$ & 20 & 6 & $11.65 \pm 0.98$ & - & - & - \\
\hline & fluoxetine & $40 \mathrm{mg}$ & 20 & 6 & $12.30 \pm 0.88$ & - & - & - \\
\hline \multirow[t]{2}{*}{$\begin{array}{l}\text { Basti (2007) } \\
{[30]}\end{array}$} & $\begin{array}{l}\text { petal of Crocus } \\
\text { sativus }\end{array}$ & $30 \mathrm{mg}$ & 19 & 8 & $12.00 \pm 0.94$ & - & - & - \\
\hline & fluoxetine & $20 \mathrm{mg}$ & 19 & 8 & $13.50 \pm 1.13$ & - & - & - \\
\hline \multirow[t]{2}{*}{$\begin{array}{l}\text { Moshiri } \\
(2006) \text { [31] }\end{array}$} & $\begin{array}{l}\text { petal of Crocus } \\
\text { sativus }\end{array}$ & $30 \mathrm{mg}$ & 19 & 6 & $14.01 \pm 1.27$ & - & - & - \\
\hline & placebo & - & 17 & 6 & $5.05 \pm 1.12$ & - & - & - \\
\hline \multirow{2}{*}{$\begin{array}{l}\text { Noorbala } \\
(2005) \text { [22] }\end{array}$} & saffron & $30 \mathrm{mg}$ & 19 & 6 & $12.20 \pm 1.07$ & - & - & - \\
\hline & fluoxetine & $20 \mathrm{mg}$ & 19 & 6 & $15.00 \pm 1.35$ & - & - & - \\
\hline \multirow{2}{*}{$\begin{array}{l}\text { Akhondzadeh } \\
\text { (2005) [21] }\end{array}$} & saffron & $30 \mathrm{mg}$ & 19 & 6 & $12.20 \pm 1.07$ & - & - & - \\
\hline & placebo & - & 16 & 6 & $5.10 \pm 1.18$ & - & - & - \\
\hline \multirow{2}{*}{$\begin{array}{l}\text { Akhondzadeh } \\
\text { (2004) [32] }\end{array}$} & saffron & $30 \mathrm{mg}$ & 15 & 6 & approx. 10 & - & - & - \\
\hline & imipramine & $100 \mathrm{mg}$ & 15 & 6 & approx. 10 & - & - & - \\
\hline
\end{tabular}

\begin{tabular}{|c|c|c|c|c|c|c|c|}
\hline \multirow[t]{2}{*}{$\underline{\text { Study name }}$} & \multicolumn{7}{|c|}{ Statistics for each study } \\
\hline & $\begin{array}{l}\text { Hedges's } \\
\text { g }\end{array}$ & $\begin{array}{l}\text { Standard } \\
\text { error }\end{array}$ & Variance & $\begin{array}{l}\text { Lower } \\
\text { limit }\end{array}$ & $\begin{array}{l}\text { Upper } \\
\text { limit }\end{array}$ & z-Value & p-Va \\
\hline Tabeshpour, 2017 & 0,280 & 0,256 & 0,066 & $-0,222$ & 0,782 & 1,094 & \\
\hline Abedimanesh, 2017 & 0,462 & 0,318 & 0,101 & $-0,162$ & 1,085 & 1.452 & \\
\hline Kashani, 2018 & 0,739 & 0,273 & 0,074 & 0,205 & 1,273 & 2,710 & \\
\hline Akhondzadeh, 2005 & 1,482 & 0,360 & 0,130 & 0,776 & 2,188 & 4,114 & \\
\hline \multirow[t]{2}{*}{ Moshiri, 2006} & 1,709 & 0,384 & 0,147 & 0,957 & 2,461 & 4,456 & \\
\hline & 0,891 & 0.266 & 0,071 & 0,369 & 1,412 & 3,348 & \\
\hline
\end{tabular}

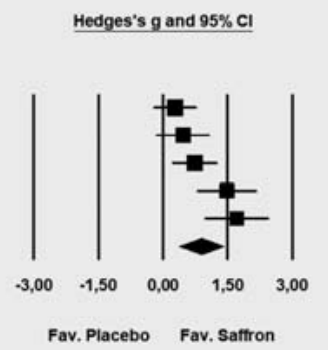

Fig. 2 Effects of saffron on the severity of mild to moderate depression compared to placebo in a random effects model $(n=5)$.

to a case report, even anaphylactic reactions can develop in patients with multiple allergies [40]. Apart from hypersensitivity, no other serious adverse events ascribed to saffron are reported in the literature. Our analysis confirmed the relative safety of saffron and its active constituents, since the incidence of adverse events was not statistically different between the saffron and placebo groups. However, the number of patients involved in the analyzed studies was relatively low, therefore a comprehensive evaluation 

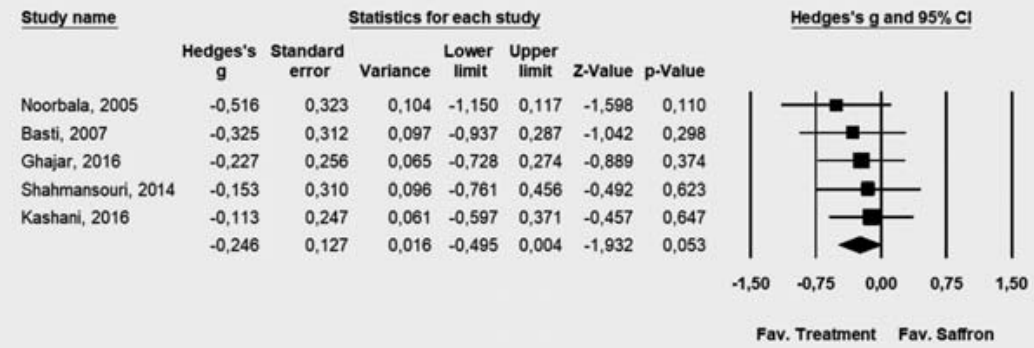

- Fig. 3 Effects of saffron on the severity of mild to moderate depression compared to synthetic antidepressants in a fixed effects model ( $n=5$ ).

of safety is required through further clinical studies and pharmacovigilance activities.

In summary, our results clearly suggest that saffron reduces the severity of depression based on HAM-D and BDI scores, but the optimum dose and duration of treatment is still unclear. In the analyzed studies, the frequency of adverse reactions did not differ significantly from that of the placebo groups. Considering the limitations, a prudent conclusion is that further and larger trials, performed by independent research groups and employing standard endpoints, are needed to assess the efficacy of saffron with a lower risk of bias.

\section{Methods}

The meta-analysis was reported according to PRISMA protocol [41]. Literature searches were conducted before February 9, 2018 using the following search queries: [("saffron"/exp OR saffron) AND ("depression"/exp OR depression)] for EMBASE; [(“crocus"[MeSH Terms] OR "crocus"[All Fields] OR "saffron"[All Fields]) AND ("depressive disorder"[MeSH Terms] OR ("depressive"[All Fields] AND "disorder"[All Fields]) OR "depressive disorder"[All Fields] OR "depression"[All Fields] OR "depression"[MeSH Terms])] for PubMed; ["saffron AND depression in Title, Abstract, Keywords in Trials"] for the Cochrane Central Register of Controlled Trials; and [TOPIC: (saffron AND depression) Timespan: All years. Indexes: SCI-EXPANDED, SSCI, A\&HCI, ESCI.] for Web of Science. To reveal all relevant studies, the reference lists of all identified articles were inspected. No language, publication date, or publication status restrictions were declared. For the purpose of transparency, this meta-analysis was based only on publicly available data, and neither the authors of the included articles nor the manufacturers of the saffron products used in the included trials were contacted to obtain additional information.

\section{Eligibility criteria}

All randomized, controlled trials that evaluated the effects of pharmacological doses of saffron (C. sativus L.) administered per os to patients suffering from mild to moderate depression were included. The comparator could be placebo or any of the routinely used antidepressant drugs. Trials that studied combinations of saffron with other treatments as well as studies without an explicit description of the applied product were excluded. Abstracts, con- ference abstracts, case series, and case reports were also excluded.

\section{Study selection}

The Mendeley 1.17.9 software package was used for record management. After removing duplicates and records without an abstract, the remaining records were screened for eligibility by two authors (B.T., D.C.) based on the title and abstract of the published original papers. The eligibility of the full texts of the remaining records was assessed by two reviewers independently (B. T., D.C.). Disagreement between reviewers was resolved by discussion or, if it was necessary, by consulting with a third reviewer (T.K.).

\section{Data extraction and synthesis of the results}

Study characteristics and results were extracted independently by two reviewers. Differences in extracted data were resolved by discussion.

The following data items were extracted from the included papers: characteristics of study design, characteristics of the patient population and sample size, intervention details, type of comparator, outcome measures, and overall results. Data on depression severity (HAM-D and BDI scores) were extracted as an outcome measure.

\section{Risk of bias}

For the quantitative analyses, each included study was evaluated by two authors using the Cochrane Collaboration tool for assessing the risk of bias, along seven specific domains: random sequence generation, allocation concealment, blinding of participants and personnel, blinding of outcome assessment, incomplete outcome data, selective reporting, and other sources of bias. For each domain, studies were judged to have a high (red), unclear (yellow), or low (green) risk of bias (Figs. 1S and 2S, Supporting Information). Disagreement regarding the quality of included studies were resolved by discussion. Risk of bias summary table and figure were generated by the RevMan 5 software [42].

\section{Statistical analyses}

Hedges' g with 95\% confidence intervals was selected for the calculation of effect sizes, as it adjusts for bias in small samples by weighting the pooled standard deviations by sample size [43]. 
Fisher's exact test (two-sided) was used for the assessment of clinical complications and adverse reactions. Heterogeneity was tested by both performing Cochran's $Q$ test [44] and calculating Higgins' $P$ indicator [45]. The $Q$ statistic was computed as the weighted sum of individual study effects' squared deviations from the pooled effect, with the weights being used in the pooling method. P values were obtained by comparing the test statistics with a chi-square with $k$ - 1 degrees of freedom (where $k$ was the number of studies). A p value of less than 0.05 was considered suggestive of significant heterogeneity. The $R$ index corresponds to the percentage of total variability across studies resulting from heterogeneity. Based on Cochrane's handbook, a rough classification of the $R^{2}$ index is as follows: low $(0-40 \%)$, moderate (30$60 \%$ ), substantial (50-90\%), and considerable variability (75$100 \%$ ) [42]. Depending on the magnitude of heterogeneity, a fixed effects model (using the Mantel-Haenszel method) [46] or a random effects model (using the DerSimonian-Laird method) [47] was employed. All the statistical analyses were performed using Comprehensive Meta-Analysis software (version 3, Biostat Inc.).

\section{Supporting information}

Risk of bias summary, risk of bias graph, and a summary of clinical complications and adverse reactions are available as Supporting information. The list of excluded studies and the reasons for exclusion are also presented as Supporting Information.

\section{Acknowledgements}

This study was supported by an Economic Development and Innovation Operative Programme Grant (GINOP 2.3.2-15-2016-00048 to P.H.) and an Institutional Developments for Enhancing Intelligent Specialization Grant (EFOP-3.6.2-16-2017-0006) awarded by the National Research, Development and Innovation Office, a János Bolyai Research Scholarship awarded by the Hungarian Academy of Sciences (to D. C.), and a research grant (115796) awarded by the National Research, Development and Innovation Office (to D. C.). The authors thank Dora Bokor, PharmD, for proofreading the manuscript.

\section{Conflict of Interest}

The authors declare no conflict of interest.

\section{References}

[1] Depression and Other Common Mental Disorders: Global Health Estimates. Geneva: World Health Organization; 2017. Licence: CC BYNC-SA 3.0 IGO. Available at http://www.who.int/mental_health/ management/depression/prevalence_global_health_estimates/en/. Accessed July 3, 2018

[2] Arroll B, Elley CR, Fishman T, Goodyear-Smith FA, Kenealy T, Blashki G, Kerse N, Macgillivray S. Antidepressants versus placebo for depression in primary care. Cochrane Database Syst Rev 2009; (3): CD007954

[3] Magni LR, Purgato M, Gastaldon C, Papola D, Furukawa TA, Cipriani A, Barbui C. Fluoxetine versus other types of pharmacotherapy for depression. Cochrane Database Syst Rev 2013; (17): CD004185

[4] Yeung KS, Hernandez M, Mao J], Haviland I, Gubili J. Herbal medicine for depression and anxiety: A systematic review with assessment of potential psycho-oncologic relevance. Phytother Res 2018; 32: 865-891
[5] Javadi B, Sahebkar A, Emami SA. A survey on saffron in major islamic traditional medicine books. Iran J Basic Med Sci 2013; 16: 1-11

[6] Bukhari SI, Manzoor M, Dhar MK. A comprehensive review of the pharmacological potential of Crocus sativus and its bioactive apocarotenoids. Biomed Pharmacother 2018; 98: 733-745

[7] Shafiee M, Arekhi S, Omranzadeh A, Sahebkar A. Saffron in the treatment of depression, anxiety and other mental disorders: Current evidence and potential mechanisms of action. J Affect Disord 2018; 227: 330-337

[8] Fernandes BS, Dean OM, Dodd S, Malhi GS, Berk M. N-Acetylcysteine in depressive symptoms and functionality: a systematic review and metaanalysis. J Clin Psychiatry 2016; 77: e457-e466

[9] $\mathrm{Ng}$ QX, Koh SSH, Chan HW, Ho CYX. Clinical use of curcumin in depression: a meta-analysis. J Am Med Dir Assoc 2017; 18: 503-508

[10] Black CN, Bot M, Scheffer PG, Cuijpers P, Penninx BW. Is depression associated with increased oxidative stress? A systematic review and metaanalysis. Psychoneuroendocrinology 2015; 51: 164-175

[11] Liu T, Zhong S, Liao X, Chen J, He T, Lai S, Jia Y. A meta-analysis of oxidative stress markers in depression. PLoS One 2015; 10: e0138904

[12] Moosavi SM, Ahmadi M, Amini M, Vazirzadeh B. The effects of 40 and $80 \mathrm{mg}$ hydro- alcoholic extract of Crocus sativus in the treatment of mild to moderate depression. J Mazandaran Univ Med Sci 2014; 24: 47-53

[13] Akhondzadeh Basti A, Choreishi SA, Noorbala AA, Akhondzadeh SH, Rezazadeh SH. Petal and stigma of Crocus sativus L. in the treatment of depression: a pilot double - blind randomized trial. J Med Plants Res 2008; 7: 29-36

[14] Lopresti AL, Drummond PD. Efficacy of curcumin, and a saffron/curcumin combination for the treatment of major depression: A randomised, double-blind, placebo-controlled study. J Affect Disord 2017; 207: 188196

[15] Cicero AF, Bove M, Colletti A, Rizzo M, Fogacci F, Giovannini M, Borghi C. Short-term impact of a combined nutraceutical on cognitive function, perceived stress and depression in young elderly with cognitive impairment: A pilot, double-blind, randomized clinical trial. J Prev Alzheimers Dis 2017; 4: 12-15

[16] Jelodar G, Javid Z, Sahraian A, Jelodar S. Saffron improved depression and reduced homocysteine level in patients with major depression: A randomized, double-blind study. Avicenna J Phytomed 2018; 8: 43-50

[17] Sahraian A, Jelodar S, Javid Z, Mowla A, Ahmadzadeh L. Study the effects of saffron on depression and lipid profiles: A double blind comparative study. Asian J Psychiatr 2016; 22: 174-176

[18] Jam IN, Sahebkar AH, Eslami S, Mokhber N, Nosrati M, Khademi M, Foroutan-Tanha M, Ghayour-Mobarhan M, Hadizadeh F, Ferns G, Abbasi $M$. The effects of crocin on the symptoms of depression in subjects with metabolic syndrome. Adv Clini Exp Med 2017; 26: 925-930

[19] Talaei A, Hassanpour Moghadam M, Sajadi Tabassi SA, Mohajeri SA. Crocin, the main active saffron constituent, as an adjunctive treatment in major depressive disorder: a randomized, double-blind, placebo-controlled, pilot clinical trial. J Affect Disord 2015; 174: 51-56

[20] Moazen-Zadeh E, Abbasi SH, Safi-Aghdam $H$, Shahmansouri $N$, Arjmandi-Beglar A, Hajhosseinn Talasaz A, Salehiomran A, Forghani S, Akhondzadeh S. Effects of saffron on cognition, anxiety, and depression in patients undergoing coronary artery bypass grafting: a randomized double-blind placebo-controlled trial. J Altern Complement Med 2018; 24: $361-368$

[21] Akhondzadeh S, Tahmacebi-Pour N, Noorbala AA, Amini H, Fallah-Pour $\mathrm{H}$, Jamshidi AH, Khani M. Crocus sativus L. in the treatment of mild to moderate depression: a double-blind, randomized and placebo-controlled trial. Phytother Res 2005; 19: 148-151

[22] Noorbala AA, Akhondzadeh S, Tahmacebi-Pour N, Jamshidi AH. Hydroalcoholic extract of Crocus sativus L. versus fluoxetine in the treatment of mild to moderate depression: a double-blind, randomized pilot trial. J Ethnopharmacol 2005; 97: 281-284 
[23] Kashani L, Esalatmanesh S, Eftekhari F, Salimi S, Foroughifar T, Etesam F, Safiaghdam H, Moazen-Zadeh E, Akhondzadeh S. Efficacy of Crocus sativus (saffron) in treatment of major depressive disorder associated with post-menopausal hot flashes: a double-blind, randomized, placebo-controlled trial. Arch Gynecol Obstet 2018; 297: 717-724

[24] Abedimanesh N, Ostadrahimi A, Bathaie SZ, Abedimanesh S, Motlagh B, Jafarabadi MA, Sadeghi MT. Effects of saffron aqueous extract and its main constituent, crocin, on health-related quality of life, depression, and sexual desire in coronary artery disease patients: A double-blind, placebo-controlled, randomized clinical trial. Iranian Red Crescent Med J 2017; 19: e13676

[25] Tabeshpour J, Sobhani F, Sadjadi SA, Hosseinzadeh H, Mohajeri SA, Rajabi O, Taherzadeh Z, Eslami S. A double-blind, randomized, placebocontrolled trial of saffron stigma (Crocus sativus L.) in mothers suffering from mild-to-moderate postpartum depression. Phytomedicine 2017; 36: 145-152

[26] Ghajar A, Neishabouri SM, Velayati N, Jahangard L, Matinnia N, Haghighi M, Ghaleiha A, Afarideh M, Salimi S, Meysamie A, Akhondzadeh S. Crocus sativus L. versus citalopram in the treatment of major depressive disorder with anxious distress: a double-blind, controlled clinical trial. Pharmacopsychiatry 2017; 50: 152-160

[27] Kashani L, Eslatmanesh S, Saedi N, Niroomand N, Ebrahimi M, Hosseinian M, Foroughifar T, Salimi S, Akhondzadeh S. Comparison of saffron versus fluoxetine in treatment of mild to moderate postpartum depression: a double-blind, randomized clinical trial. Pharmacopsychiatry 2017; 50: 64-68

[28] Mazidi M, Shemshian M, Mousavi SH, Norouzy A, Kermani T, Moghiman T, Sadeghi A, Mokhber N, Ghayour-Mobarhan M, Ferns GAA. A doubleblind, randomized and placebo-controlled trial of Saffron (Crocus sativus L.) in the treatment of anxiety and depression. J Complement Integr Med 2016; 13: 195-199

[29] Shahmansouri N, Farokhnia M, Abbasi SH, Kassaian SE, Noorbala Tafti AA, Gougol A, Yekehtaz H, Forghani S, Mahmoodian M, Saroukhani S, Arjmandi-Beglar A, Akhondzadeh S. A randomized, double-blind, clinical trial comparing the efficacy and safety of Crocus sativus L. with fluoxetine for improving mild to moderate depression in post percutaneous coronary intervention patients. J Affect Disord 2014; 155: 216-222

[30] Basti AA, Moshiri E, Noorbala AA, Jamshidi AH, Abbasi SH, Akhondzadeh S. Comparison of petal of Crocus sativus $L$. and fluoxetine in the treatment of depressed outpatients: a pilot double-blind randomized trial. Prog Neuropsychopharmacol Biol Psychiatry 2007; 31: 439-442

[31] Moshiri E, Basti AA, Noorbala AA, Jamshidi AH, Hesameddin Abbasi S, Akhondzadeh S. Crocus sativus L. (petal) in the treatment of mild-to- moderate depression: a double-blind, randomized and placebo-controlled trial. Phytomedicine 2006; 13: 607-611

[32] Akhondzadeh S, Fallah-Pour H, Afkham K, Jamshidi AH, KhalighiCigaroudi F. Comparison of Crocus sativus L. and imipramine in the treatment of mild to moderate depression: a pilot double-blind randomized trial [ISRCTN45683816]. BMC Complement Altern Med 2004; 4: 12

[33] Khanali M, Shahvarooghi Farahani S, Shojaei H, Elhami B. Life cycle environmental impacts of saffron production in Iran. Environ Sci Pollut Res Int 2017; 24: 4812-4821

[34] Hausenblas HA, Saha D, Dubyak PJ, Anton SD. Saffron (Crocus sativus L.) and major depressive disorder: a meta-analysis of randomized clinical trials. J Integr Med 2013; 11: 377-383

[35] Hamilton M. A rating scale for depression. J Neurol Neurosurg Psychiatry 1960; 23: 56-62

[36] Beck AT, Steer RA. Beck Depression inventory Manual. New York: Guildford Press; 1993

[37] Beck AT, Steer RA, Brown GK. Manual for the Beck Depression InventoryII. San Antonio: Psychological Corporation; 1996

[38] Schmidt M, Betti G, Hensel A. Saffron in phytotherapy: pharmacology and clinical uses. Wien Med Wochenschr 2007; 157: 315-319

[39] Ayatollahi H, Javan AO, Khajedaluee M, Shahroodian M, Hosseinzadeh H. Effect of Crocus sativus L. (saffron) on coagulation and anticoagulation systems in healthy volunteers. Phytother Res 2014; 28: 539-543

[40] Wüthrich B, Schmid-Grendelmeyer P, Lundberg M. Anaphylaxis to saffron. Allergy 1997; 52: 476-477

[41] Moher D, Liberati A, Tetzlaff J, Altman DG, The PRISMA Group. Preferred reporting items for systematic reviews and meta-analyses: the PRISMA statement. PLoS Med 2009; 6: e1000097

[42] Higgins JPT, Green S, eds. Cochrane handbook for systematic reviews of interventions, version 5.1.0. The Cochrane Collaboration. Available at www.handbook.cochrane.org. Accessed February 26, 2018

[43] Hedges L. Distribution theory for Glass's estimator of effect size and related estimators. J Educ Behav Stat 1981; 6: 107-128

[44] Cochran WG. The combination of estimates from different experiments. Biometrics 1954; 10: 101-129

[45] Higgins JP, Thompson SG, Deeks J], Altman DG. Measuring inconsistency in meta-analyses. BMJ 2003; 327: 557-560

[46] Mantel N, Haenszel W. Statistical aspects of the analysis of data from retrospective studies of disease. J Natl Cancer Inst 1959; 22: 719-748

[47] DerSimonian R, Laird N. Meta-analysis in clinical trials. Control Clin Trials 1986; $7: 177-188$ 